Clemson University

TigerPrints

$1-2015$

\title{
Examining the Effects of Preschool Writing Instruction on Emergent Literacy Skills: A Systematic Review of the Literature
}

\author{
Anna H. Hall \\ Clemson University, ah2@clemson.edu \\ Amber Simpson \\ Clemson University \\ Ying Guo \\ University of Cincinnati - Main Campus \\ Shanshan Wang \\ University of Cincinnati - Main Campus
}

Follow this and additional works at: https://tigerprints.clemson.edu/eugene_pubs

Part of the Education Commons

\section{Recommended Citation}

Anna H. Hall, Amber Simpson, Ying Guo \& Shanshan Wang (2015) Examining the Effects of Preschool Writing Instruction on Emergent Literacy Skills: A Systematic Review of the Literature, Literacy Research and Instruction, 54:2, 115-134, DOI: 10.1080/19388071.2014.991883

This Article is brought to you for free and open access by the Eugene T. Moore School of Education at TigerPrints. It has been accepted for inclusion in Publications by an authorized administrator of TigerPrints. For more information, please contact kokeefe@clemson.edu. 
Examining the Effects of Preschool Writing Instruction on Emergent Literacy Skills: A Systematic Review of the Literature

\author{
Anna H. Hall ${ }^{1}$, Amber Simpson ${ }^{1}$, Ying Guo ${ }^{2}$, and Shanshan Wang ${ }^{2}$ \\ ${ }^{1}$ Eugene T. Moore School of Education, Clemson University \\ ${ }^{2}$ School of Education, University of Cincinnati
}

Address correspondence to Anna H. Hall, 407B Tillman Hall, Clemson University, Clemson, South Carolina 29634. Email: ah2@clemson.edu 
Examining the Effects of Preschool Writing Instruction on Emergent Literacy Skills:

A Systematic Review of the Literature

Although expectations for young children to write have increased significantly in recent years (National Governors Association Center for Best Practices \& Council of Chief State School Officers [NGA \& CCSSO, 2010) and support exists for engaging preschool children in meaningful writing experiences (Atwell, 1987; Calkins, 1983; Clay, 1991; Graves, 1983; Teale \& Sulzby, 1986), little information exists regarding effective writing instruction in the preschool setting. Conducting a systematic review of experimental research is a useful approach for identifying instructional strategies in writing that hold promise for improving young children's emergent literacy skills (Graham, McKeown, Kiuhara, \& Harris, 2012). Thus, the purpose of this article is to provide a systematic review of experimental studies investigating preschool writing instruction along with a meta-analysis component. Due to the interrelated nature of emergent literacy skills, experimental research in the preschool setting often includes multifaceted interventions (i.e., interventions that include instruction in multiple literacy domains), making it challenging to discern the effects of specific domains. Specifically, few experimental studies have been conducted with interventions focused solely on preschool writing instruction (Bernhard, Winsler, Bleiker, Ginieniewicz, \& Madigan, 2008; DeBaryshe \& Gorecki, 2007).

In this study, we used Head Start's definition of early writing as the familiarity with writing implements, conventions, and emerging skills to communicate attitudes and ideas through written representations, symbols, and letters (U.S. Department of Health and Human Services, 2010). Emergent literacy theory suggests children's early writing involves experimenting with writing and modifying understandings about print through meaningful 
interactions with the social environment and text (Clay, 1991). Emergent writing has been observed across several dimensions (e.g., writing form, directionality, ways of assigning meaning, and message content; Rowe \& Wilson, 2009) and children as young as two years of age have been observed to use early writing to explore and record ideas (Rowe \& Neizel, 2010). A growing body of research suggests emergent writing skills appear to develop at different rates, along a developmental continuum, and without a set sequence of activities (Levin et al., 2005; Puranik \& Lonigan, 2011; Tolchinksy, 2003). As children move through using their current forms (e.g., scribbles, letter strings, words) of emergent writing, they begin to notice print and to recognize and write familiar words. Graves (1983) describes children's natural desire to write. Children want to write. They want to write the first day they attend school. This is no accident. Before they went to school they marked up walls, pavements, newspapers with crayons, chalk, pens or pencils... anything that makes a mark. The child's marks say, "I am." (p. 3)

Calkins $(1983,1986)$ states that as children move through the developmental stages of writing, they experience the powerful discovery that print carries meaning. Tolchinsky (2014) emphasizes that children learn to write by consistently engaging in the act of writing and experimenting with print.

Although a large body of research supports the importance of children engaging in meaningful early writing experiences, a recent study conducted by Pelatti, Piasta, Justice, \& O'Connell (2014) shows preschool children typically engage on average in less than one minute of writing per day. Also, preschool writing instruction focuses primarily on procedural knowledge such as fine motor skills and letter formation rather than the meaning-making processes involved in writing (i.e., interpersonal communication, graphic representations, and 
recording ideas; Molfese et al., 2011). For example, learning to write names or form individual letters are frequent activities in preschool classrooms (Diamond, Gerge, \& Powell, 2008; Levin, Both-DeVries, Aram, \& Bus, 2005).

While transcription skills and procedural knowledge related to writing are essential, preschool writing goals should include helping children integrate their understandings of multiple dimensions of print so that they can apply language and literacy skills in familiar and authentic writing (Tolchinsky, 2014). Ultimately, preschool writing should aim to produce significant increases in children's learning outcomes in the following areas: (1) attitudes toward writing, (2) engagement in writing, (3) oral language skills, (4) alphabet knowledge, (5) concepts about print, (6) phonological awareness, and (7) early writing skills (e.g., communicating and representing ideas through symbols and/or letters).

Studies involving early writing have been included in meta-analyses and narrative summaries of early literacy research by The National Early Literacy Panel (NELP) and the National Research Council (NRC). NELP found evidence suggesting that name writing skills yield significant correlations with later reading abilities including decoding, reading comprehension, and spelling (NELP, 2008). NRC reported key early writing skills (e.g., writing uppercase and lowercase letters independently, writing unconventionally to express meaning, and writing letters and some words when dictated) as necessary targets of interventions to prevent future reading problems (Snow et al., 1998).

Although early writing is highlighted as an important indicator of future literacy achievement in the NELP report (2008) and narrative summaries of research (Snow et al., 1998; Whitehurst \& Lonigan, 1998), results of specific interventions are difficult to discern given the range of independent and dependent variables analyzed in these reports. This article provides a 
comprehensive systematic review of available data on the impact of preschool writing on emergent literacy outcomes. Findings from interventions are organized according to three predominant philosophical approaches to preschool writing instruction described below.

\section{Philosophical Approaches to Preschool Writing Instruction}

Preschool teaching strategies related to writing vary in terms of their philosophical approach (Craig, 2006; Roth, 2009) depending on how teachers' theoretical perspectives align with predominant views of early literacy development. A continuum of support by the teacher exists (see Figure 1), from activities where students are free to interact with writing materials in natural settings to activities where the teacher directs the writing process (Bernhard et al., 2008; Justice et al., 2003). Teachers may only incorporate one type of writing instruction during the school day or they may implement a variety of strategies along the continuum depending on their objectives and personal philosophy. Although the philosophies addressed below span a continuum of least amount of adult support to most, each philosophy is related to distinct instructional approaches as illuminated in the studies described in subsequent sections.

\section{$<$ INSERT FIGURE 1>}

The maturationist theory, advanced by the work of Arnold Gessell (1940), posits that development is a biological process that occurs in a predictable sequence over time. This perspective leads teachers to assume that children will naturally acquire isolated skills as they grow and mature (Demarest et al., 1993). The maturationist teacher views their role as an observer to determine levels of development and to arrange the classroom for learning through participation with literacy materials (DeVries, Zan, Hildebrandt, Edmiaston, \& Sales, 2002). Preschool teachers who hold maturationist beliefs often embed writing instruction in naturalistic contexts with children acquiring emergent literacy skills through frequent interactions with print 
materials and participation in self-directed activities. For example, teachers who practice a maturationist approach to writing instruction may add handwriting worksheets to the writing center or clipboards with pens to play areas to encourage informal interactions with literacyrelated artifacts (Neuman \& Roskos, 1992).

In contrast to maturationist beliefs, constructivists/interactionists believe that learning is influenced not only by the environment, but also by children's active participation and construction of knowledge through meaningful interactions with teachers and peers (Vygotsky, 1978). Constructivist theorists including Dewey, Piaget, and Vygotsky believed that learning must involve the social world of children. Therefore, constructivist teachers describe learning as an interactive process that engages children's interests, inspires active construction of knowledge, and involves adults as facilitators who are able to communicate appropriately and meaningfully with young children.

Constructivist views are consistent with what Tolchinsky (2014) terms a "mutually enhancing interactive perspective" on early writing development and emergent literacy theory. Interactionist views challenge the reading readiness philosophy which suggests that it is necessary for children to gradually master lower-level skills, such as handwriting and spelling before progressing to higher-level skills, such as idea generation and text construction (Abbott, Berninger, \& Fayol, 2010). Instead, interactionist views assume that learning to write involves simultaneous, mutually enhancing components of development (e.g., knowledge of the alphabetic system, ability to spell, understanding of letter-sound relations; definitional vocabulary) for composing and transcribing (Tolchinsky, 2014). Preschool teachers who hold constructivist/interactionist beliefs often focus on multiple skills (i.e., both lower-level and higher-level writing skills) within the same lesson or writing experience. Activities such as 
shared writing, interactive writing, journaling, and bookmaking are guided by the teacher and influenced by interactions with peers within their writing community.

A third stream in early childhood philosophy is the environmentalist/behaviorist view of child development. According to B. F. Skinner, all knowledge comes from outside the individual and therefore must be transmitted to the student by adults (DeVries et al., 2002). Environmentalists/behaviorists believe that children's environments shape their behavior and that teacher-directed learning activities are required for helping children master a set sequence of skills (Hand \& Nourot, 1999). In contrast to constructivist/interactionist views, behaviorist teachers believe that little relational interaction is necessary for helping children acquire new knowledge. For young children experiencing difficulty in the attainment of early writing skills, more direct approaches to writing instruction have been found beneficial in targeting performance in key areas such as letter identification and sounds, letter forming, and generating ideas for writing (Justice et al., 2003). Direct teaching involving systematic skill-based writing instruction focuses on teaching children how and when to apply specific writing skills. Children are shown a model of writing through teacher demonstration and then encouraged to copy the teacher example. Preschool teachers who hold environmentalist/behaviorist views often provide direct teaching aimed at improving children's letter writing, handwriting, and name writing abilities.

\section{Purpose of the Current Study}

Although much attention has been placed on early writing skills in contemporary educational policy, few rigorous evaluations of writing instruction in the preschool setting have been undertaken. Much of the literature to date on writing instruction is conducted in elementary school settings (Graham et al., 2012; Puranik, Al Otaiba, Sidler, \& Greulich, 2014). The purpose 
of this article is to provide a systematic analysis of studies investigating preschool writing instruction to improve emergent literacy skills in preschool children. Systematic reviews can include a meta-analysis component, which involves synthesizing the data from several studies into a single quantitative summary effect size (Petticrew \& Roberts, 2008). Analyzing effect sizes allows for a principal synthesis of results across studies and thus provides a practical and conceptual understanding of the average impact of preschool writing instruction. We selected this approach due to the small number of studies available for examination. The article is further divided into three sections, Method, Results, and Discussion, in which we discuss our search to find pertinent research articles, our condensation of reported findings, and our reflections of the findings. The Results section comprises three parts: (a) Maturationist Intervention, (b) Constructivist/Interactionist Interventions, and (c) Environmentalist/Behaviorist Interventions.

\section{Method}

\section{Selection of Studies}

To be included in this systematic review, an article had to meet the following criteria: (a) be an experimental or quasi-experimental study involving writing as part of an intervention, (b) be published in a peer-reviewed journal published between 1990-2013, (c) be conducted in a Head Start, day care, or state funded preschool setting with children ages 3 to 5 years, not yet enrolled in Kindergarten, (d) not be limited to a particular subgroup such as children with special needs or English Language Learners, and (e) be written in English.

A thorough literature search was conducted for articles on interventions involving early writing skills, broadly defined as students' familiarity with writing implements, recognition of writing as a way of communicating for a variety of purposes, and use of scribbles, shapes, pictures, or letters to represent attitudes and ideas (Halle, Hair, Wandner, \& Chien, 2012; U.S. 
Department of Health and Human Services, 2010). Five specific techniques were used to locate possible studies for inclusion in this systematic review. First, Academic Search Complete, Education Full Text, Education Research Complete, ERIC, and PsychINFO Databases were searched for full text articles. An initial search of the databases included each of the following search terms: composition, early writing, emergent writing, guided writing, handwriting, interactive writing, journals, journal writing, name writing, shared writing, writing ability, writing achievement, writing attitudes, writing contexts, writing development, writing difficulties, writing evaluation, writing improvement, writing instruction, writing motivation, writing processes, writing readiness, writing research, writing skills, and writing strategies. A subsequent search included combining each of these search terms with early childhood, as well as with the term preschool. If a potential article's abstract suggested that the article fit within our criteria, yet was not in the library's database (e.g. due to the limited range of years of library's subscription to a particular journal), we used InterLibrary Loan to obtain the article.

Second, the reference list from the meta-analysis conducted by the National Early Literacy Panel (2008) was examined to identify potentially appropriate studies. Third, a hand search of Journal of Teaching Writing (from 2007 to 2013) and Reading and Writing: An Interdisciplinary Journal was conducted (from 1990 to 2013). Fourth, the reference lists in the collected experimental and quasi-experimental studies were cross-referenced to locate additional articles and papers. Lastly, Google Scholar was utilized to find "Related Articles" for each included study.

\section{Strategies for Categorizing Studies}

This systematic review of the literature is organized around the set of philosophical approaches described earlier, namely maturationist, constructivist/interactionist, and 
environmentalist/behaviorist. Due to the multifaceted interventions found in the majority of studies related to preschool writing, we categorized studies based solely on the writing component of the intervention. For example, if an intervention was composed of phonemic awareness games, magnetic alphabet letter exploration, and direct name writing instruction, we coded the study as a behaviorist writing intervention based only on the direct name writing instruction component of the intervention.

The multiple searches yielded thousands of hits, and based on the titles and abstracts, the hits were narrowed to 76 potentially relevant articles. After obtaining full copies of the 76 articles, we narrowed the list to the 18 included articles by reading the full study reports and eliminating articles that did not meet the criteria as listed above. Next, an Excel document was constructed to describe and organize each study by sample, writing intervention, dependent variable(s), and findings. We used this spreadsheet as a talking point to categorize each study into the different philosophical approaches found in the literature. After coding and categorizing the studies, the authors analyzed the groups of articles for common themes using a contentanalysis approach (Neuendorf, 2002). Table 1 highlights the characteristics of the interventions from each of the included studies.

\section{$<$ INSERT TABLE $1>$}

\section{Effect Size Calculation}

Effective sizes (Hedges' $g$ ) were computed to represent the effectiveness of writing instruction on children's early literacy outcomes. Hedges' $g$, also called the standardized mean difference, is a derivation of the mean difference $(d)$ effect size and uses a correction factor $(J)$ to correct for bias from sample size. We can estimate Hedges' g from studies that used two independent groups as: $g=d \times J$. A positive effect size indicates a more favorable change in 
outcomes for the intervention condition. When studies reported more than one outcome measure, we used the average of the outcomes, which ensures independence of data and is consistent with procedures used by other meta-analyses (Borenstein, Hedges, Higgins, \& Rothstein, 2009; Marulis \& Neuman, 2010). In addition, when studies included multiple conditions (e.g., two intervention conditions and one control condition), we calculated multiple effect sizes per study. For this systematic review of the literature, a random-effects model was used to estimate a summary effect and its $95 \%$ confidence interval (CI). Under the randomeffects model, we assumed that the magnitude of the effectiveness of interventions may vary from study to study, due to a number of factors, such as context of intervention, type of intervention, and so on. All the analyses were conducted in the R statistical software using the meta package version 3.1-2 (Schwarzer, 2013).

\section{Results}

\section{Maturationist Intervention}

Only one experimental study was found that examined the effects of enhancing the physical literacy environment with print materials including writing implements and paper (Neuman \& Roskos, 1992) without adult involvement. The effect size for this study was $g=.94$ (see Table 1) which is considered a large effect size (Cohen, 1988). Neuman and Roskos (1992) used a pre-post control group design to explore the effects of physical design changes and the introduction of literacy objects in the children's natural environment on their spontaneous free play. Statistically significant differences were reported in each category of response including their handling, reading, and writing behaviors, indicating that children exposed to a literacyenhanced play area were likely to engage in lengthier $(p<.001)$ and more complex literacyrelated play $(p<.001)$ than children in unenhanced play areas. For example, children in the 
intervention group engaged in meaningful activities such as addressing and sending mail while children in the control group were more likely to engage in less authentic tasks such as identifying words and letters on available print in the classroom. This study indicates strong implications for enhancing play settings with literacy objects that can stimulate and engage children's interest in functional reading and writing.

\section{Constructivist/Interactionist Interventions}

Adult involvement in literacy-enhanced play centers has been found to extend the benefits of physical design changes by providing modeling and guidance (Bernhard et al., 2008; Justice et al., 2003). Eight studies were found that examined constructivist/interactionist writing strategies including adult modeling and support, journaling, bookmaking, interactive writing, and shared writing. We calculated effect sizes for five of these studies, which represented eight distinct intervention conditions (i.e., treatment groups) ${ }^{1}$. The results in Table 1 show that the constructivist/interactionist interventions $(n=5)$ had effect sizes that ranged from small to large (.07 - 1.44). It is worth noting that the effect sizes of Morrow's (1990) intervention conditions were extremely high, ranging from 14.94 to 18.21 , and should be considered as outliers.

Adult modeling and support interventions. Three studies (Christie \& Enz, 1992; Morrow, 1990; Neuman \& Roskos, 1993) examined the additional effect of adult involvement in literacy-enhanced environments on children's type and quality of literacy behaviors. Christie and Enz (1992) used a comparison study with a materials-only thematic play group and a materials plus adult modeling thematic play group. They found adult involvement (including modeling and facilitation) was more effective in encouraging literacy-related play as indicated by increases in total play $(p<.05)$ and incidents of literate play, defined as "emergent forms of

\footnotetext{
${ }^{1}$ Three studies were excluded from effect size analysis due to lack of statistical evidence (e.g., means and standard deviations).
} 
reading and writing in connection with their [children's] dramatic play" (Christie \& Enz, 1992, p. 205). For example, a child who scribbles an order on a notepad while pretending to be a waitress is experimenting with an emergent form of writing that will lead toward conventional forms of writing in the future (Sulzby, 1985).

Neuman and Roskos (1993) and Morrow (1990) used multiple treatment groups to examine the effects of literacy-enhanced thematic play areas with and without adult involvement. Neuman and Roskos (1993) conducted their study in eight Head Start classrooms using two treatment groups: (1) literacy-enhanced thematic play group and (2) literacy-enhanced thematic play plus adult involvement. Neuman and Roskos (1993) found adult involvement significantly contributed to environmental word reading $(p<.001)$, while both treatment groups experienced similar increases in reading and labeling functional items using writing.

Morrow (1990) used two similar treatment groups with an additional group that was exposed to literacy materials in un-themed play areas with adult involvement. Morrow (1990) found significant differences between groups over time $(p<.001)$ with the thematic play with involvement group experiencing the greatest gains followed by the un-themed play area with adult involvement group, then the thematic play without involvement group, and the control group who were found to use the least literacy behaviors, (e.g., paper handling, scribbling, and pretend reading) during post-test observations.

Music therapy interventions. Two studies (Register, 2001; Standley \& Hughes, 1997), both with relatively small sample sizes ( $n=50, n=24$ respectively), examined the effects of music lessons specifically designed to teach and/or reinforce prereading and writing concepts on children's logo identification and print awareness skills. Standley and Hughes (1997) encouraged children to use invented spelling and combine the use of text with spoken/sung 
language during intervention activities. For example, to transfer skills taught in the music to their independent writing, children were asked to draw a picture of what they had learned during the music lesson and share their writing with the class. Children also engaged in scribbling practice as they listened to songs such as "Scribble to the Right". Standley and Hughes (1997) found no statistically significant differences between the treatment and control groups for print awareness and logo identification $(p>.05)$.

Register (2001) also included journaling following literacy music lessons. The children dictated an explanation of their journal drawing to the teacher and the teacher recorded the message directly on the child's paper. In addition, children in this study illustrated song books that were used during the music lessons and made accessible to children during other parts of the school day. Register (2001) found statistically significant differences between groups on both logo identification and print awareness skills $(p<.05)$. The results from these two studies (Register, 2001; Standley \& Hughes, 1997) suggest mixed findings for the effectiveness of music lessons plus journaling for improving early literacy outcomes.

Interactive writing intervention. One study was found examining the effects of a specific constructivist writing intervention. Hall, Toland, Grisham-Brown, and Graham (2014) examined the effects of interactive writing, a technique that allows children and teachers to "share the pen" to create a group text, on children's alphabet knowledge skills. During the 13week study, the treatment group received four 10-15 minute interactive writing lessons per week. During each lesson, the teacher and students negotiated a meaningful writing topic, coconstructed the oral text, shared the pen to write the text, and read the text together as a group. Significant differences were observed between the treatment and control groups for uppercase ( $p$ 
$<.001)$ and lowercase $(p<.001)$ letter identification, but no differences were observed between groups for letter sound identification.

Comprehensive curriculum interventions. DeBaryshe and Gorecki (2007) and Bernhard et al. (2008) investigated constructivist writing strategies within a comprehensive early literacy curriculum. DeBaryshe and Gorecki (2007) pilot tested the literacy and math components of the Learning Connections Curriculum separately by using a literacy-only treatment group, math-only treatment group, and a control group. Along with dialogic reading, adult-child conversations, and phonemic awareness activities, the intervention included shared writing (e.g., morning message), interactive writing (e.g., teacher and children worked together to compose and write a class book of signs and environmental print), journaling with teacher prompts, and bookmaking. Significant differences were found between literacy-only and mathonly groups for phonemic awareness $(p=.003)$, emergent reading $(p=.004)$, and emergent writing skills consisting of both name and word writing skills $(p=.001)$, as well as between literacy-only and control groups ( $p=.002, p=.035$, respectively).

Bernhard et al. (2008) examined the effects of the Early Authors Program, a 12-month intervention program conducted with 1,179 children and their teachers, families and literacy specialists/interventionists focused on bookmaking. The literacy specialists provided extensive training and bookmaking materials to teachers during this large scale study. Children were encouraged to use their home language, technology, and personal photographs to create meaningful books that could be shared with their classmates and families. Significant differences were found in children's language development including expressive communication and audio comprehension skills $(p<.01)$ during post-tests and teachers noted increases in the 
quality of their literacy environment and the frequency with which they engaged with children in literacy activities in the classroom as a result of the intervention.

\section{Environmentalist/Behaviorist Interventions}

Of the 17 experimental and quasi-experimental studies found in the literature search, nine examined the effects of systematic and/or teacher-directed writing instruction. We calculated effect sizes for seven of these studies, which represented 13 distinct intervention conditions ${ }^{2}$. The results in Table 1 show that the effect sizes of behaviorist/environmentalist interventions differed significantly from study to study, particularly due to the nature of the intervention condition employed. One intervention condition demonstrated a large effect size (i.e., Hedges' $g$ $=.91$ ), seven intervention conditions showed a small to medium effect size (i.e., $.21 \leq$ Hedges' $g$ $\leq .6)$, and the other interventions condition $(n=5)$ produced minimal effect sizes, ranging from .06 to .18 .

Interventions targeting name writing activities to increase early literacy skills (Justice et al., 2003; Vera, 2011) were implemented in two studies. Four studies examined systematic letter writing activities including naming, identifying, and writing letters (Aram, 2006; Aram \& Biron, 2004; Lonigan, Farver, Phillips, \& Clancy-Menchetti, 2011; Neumann, Hood, \& Ford, 2013). The remaining three studies implemented interventions focused on improving handwriting including body awareness, the use of adapted writing tools, and following a correct model (Donica, Goins, \& Wagner, 2013; Longcamp, Zerbato-Poudou, \& Velay, 2005; Lust \& Donica, 2011). The handwriting studies differed from the letter writing studies in that their emphasis was more on fine motor readiness skills versus alphabet letter knowledge and formation.

\footnotetext{
${ }^{2}$ Two studies were excluded from effect size analysis due to lack of statistical evidence (e.g., means and standard deviations).
} 
Name writing interventions. Two studies incorporated writing interventions that provided meaningful connections for children through the writing of familiar names. Justice et al. (2003) used a sign-in procedure with children writing their own names while Vera (2011) incorporated a writing activity with children writing well-known names (e.g., Dora) in popular culture (Vera, 2011). Although children were able to connect to the text through familiarity in both of these studies, the sign-in procedure (Justice et al., 2003) and the cloze or fill in the blank activity (Vera, 2011) were very teacher directed in that children had to trace their names or write the name of the popular culture character as demonstrated by the teacher, respectively.

Justice et al. (2003) utilized an alternating intervention program with an experimental emergent literacy program (including name writing, alphabet recitation, and phonological awareness games) and a comparison program focused on storybook reading and story retelling. Results demonstrated that children in the explicit emergent literacy program involving writing improved significantly on alphabet knowledge $(p=.000)$, print awareness $(p=.004)$, name writing $(p=.03)$, phonological segmentation $(p=.000)$, and rhyme production $(p=.003)$, while children in the comparison program improved significantly only on phonological segmentation $(p=.02)$.

Vera (2011) implemented a comprehensive curriculum to incorporate popular culture print into the literacy environment and literacy activities using a pretest, intervention, posttest sequence with a treatment and control group. The treatment group received whole group and small group writing lessons during the nine week intervention. The whole group writing component of the curriculum, although termed as shared writing, was described as a teacher directed cloze activity where all children were directed by the teacher to write the same letters and words simultaneously. The small group writing component used a similar lesson format, but 
allowed children to choose a familiar cartoon character before filling in the blank for the cloze sentence. Vera (2011) concluded that children in the treatment group scored significantly higher in alphabet knowledge $(p=.01)$ and print concepts $(p=.00)$.

Letter writing interventions. Lonigan et al. (2011) and Neumann et al. (2013) used multifaceted interventions, which included letter writing activities led by the teacher. In the study conducted by Neumann and colleagues (2013), a teacher used a magnetic board to model writing letters while using directional language. Following the teacher demonstration, the children were asked to write the letter in the sky and then in their personal blank writing book. Lonigan and colleagues (2011) randomly assigned 48 preschools to one of two literacy-focused curriculum groups (one with workshop only professional development and one with workshop plus in-class mentoring professional development) and a control group. The literacy focused curriculum was the Literacy Express Preschool Curriculum (LEPC), in which one of the teacher directed activities was to promote the development of print knowledge through activities that introduced the names and sounds of letters and encouraged children to begin writing individual letters in their name. Results revealed that children in the both LEPC groups scored significantly higher at the end of the intervention than the control group on expressive language $(p<.05)$, phonological awareness $(p<.01)$, and print knowledge $(p<.05)$.

Neumann and colleagues (2013) examined differences in progress among children in one of three groups: environmental print (i.e., print on objects such as grocery products, clothing, and billboards), standard print (i.e., print found in storybooks or written on index cards), and control. The two interventions were 30 minute, weekly small group sessions that occurred over an 8week period. The intervention programs were identical with the exception that one included writing activities with environmental print, while the other included writing activities with 
standard print. Letters were introduced each week through various writing activities such as forming letters in the sky, tracing them with their fingers, and writing the letters on paper. The researchers determined that the children in both intervention groups progressed significantly more from pretests to posttests than the control group on all dependent variables including letter writing and standard print reading. In regards to the two intervention groups, children in the environmental print program progressed significantly more than children in the standard print program in environmental print reading $(p<.001)$ and print motivation $(p=.042)$.

In the studies conducted by Aram and Biron (2004) and Aram (2006), small groups of 46 children received an intervention involving games and activities focusing on letter knowledge, phonological awareness, and writing skills for approximately 20 to 30 minutes a week, twice a week. One of the writing activities within these scripted lessons were writing words with objects, other than a pencil, such as stickers. Aram and Biron (2004) included three groups in their study: a joint writing program, a joint reading program, and a control group. Results demonstrated a significant difference in word writing $(p=.0001)$ and phonological awareness $(p$ $=.000$ ) between the joint writing group and the other two groups. It was further noted that the joint writing group progressed significantly different in letter knowledge $(p=.001)$ compared to the joint reading group and in orthographic awareness $(p=.000)$ compared to the control group. Building upon this study, Aram (2006) included a fourth group, a combined reading-writing intervention. During one week, children in this group would receive one session on developing their reading skills and another session on developing their writing skills; thus, receiving the same activities as the joint reading and joint writing groups, but not as intensely. All three treatment groups significantly surpassed the control group on three dependent variables: name writing, letter knowledge, and phonological awareness. Additionally, the children participating 
in the program with a writing component progressed significantly more than all other groups on word writing $(p<.01)$, letter knowledge $(p<.01)$, and letter retrieval $(p<.01)$.

Handwriting interventions. Lust and Donica (2011) investigated the impact of the Handwriting Without Tears (HWT) (Olsen \& Knapton, 2008) curriculum as a supplemental curriculum with children enrolled in Head Start. The purpose of this occupational based intervention writing curriculum was to develop kindergarten-ready prewriting skills by incorporating multisensory activities including singing, body awareness skills, and visualperceptual skills to name a few. The intervention was implemented for 20 minutes, three times a week from October to March. The results showed that children participating in the $H W T$ program scored significantly higher on instruments measuring prewriting skills (i.e., ability to copy first name, copy "V", print any two letters without a model, copy simple words, and copy a square; $p=.0058)$, kindergarten readiness $(p=.022)$, and fine motor skills $(p=.017)$ than children in the control group. Donica and colleagues (2013) extended the Lust and Donica (2011) study by including another supplementary writing curriculum, Fine Motor and Early Writing Pre-K Curriculum (FMEW), focused on improving handwriting skill development (e.g., fine motor skills and perceptual motor skills) by implementing adapted writing tools such as forming letters with popsicle sticks and workbook products. Unlike the previous study, no significant differences were found among children (i.e., $H W T, F M E W$, and control). However, the researchers noted that children participating in the $H W T$ curriculum showed the highest positive change in overall handwriting skills (e.g., letter writing) as measured by the Shore Handwriting Screening for Early Handwriting Development (SHS) (Shore, 2003).

Longcamp et al. (2005) investigated differences in capital letter recognition between children in a typing intervention versus a handwriting intervention. After being exposed to 
capital letters through a story read by the teachers, the two interventions occurred once a week for half an hour. The typing intervention required children to type the letters displayed on a computer screen, while the handwriting intervention required children to copy words on a piece of paper. In both interventions, the children received immediate feedback when the incorrect letter was typed or if the letter was not written. Longcamp et al. (2005) concluded that children in the handwriting intervention selected correct responses more often than children in the typing intervention $(p<.06)$, which was more prevalent among older children (mean age $=53.3$ months, $p<.02)$.

The behaviorist/environmentalist studies reviewed here show promising effects of explicit writing instruction (including letter writing and handwriting) on early literacy outcomes such as print knowledge, name and letter writing, phonological awareness, alphabet knowledge, and fine motor skills. Yet, the results must be interpreted with caution due to the limited role of writing in the multifaceted interventions. Conclusions on the effects of handwriting instruction warrant additional caution due to the limited number of studies.

\section{Discussion}

Research suggests that children as young as two years of age demonstrate early writing skills which increase and in general become more stable during the preschool years (Puranik \& Lonigan, 2011; Rowe \& Wilson, 2009). Research examining this developmental trajectory has linked children's performance on written language tasks to their conventional literacy outcomes in elementary school and beyond (Donica et al., 2013; Justice et al., 2003; Puranik \& Lonigan, 2011). Specifically, predictive studies have found links between early writing proficiency and a child's future reading ability, ease with self-expression, propensity to complete assignments, and motivation (Donica et al., 2013; Lust \& Donica, 2011; Neumann et al. 2013, Snow et al., 1998). 
Despite predictive relationships identified in recent research and increased expectations with the adoption of the Common Core State Standards (NGA \& CCSSO, 2010), preschool children spend very little time engaged in writing (Pelatti et al., 2014) and preschool writing instruction focuses primarily on procedural knowledge rather than discursive processes (Tolchinsky, 2014). Consequently, identifying approaches for intervening in the area of early writing skills is timely and warranted.

The primary purpose of this article is to provide a systematic analysis of research studies investigating preschool writing instruction to improve children's emergent literacy skills. This systematic review with a meta-analysis component builds on previous meta-analyses and narrative summaries of research (NELP, 2008; Snow et al. 1998), which examine the effects of multiple early literacy skills on conventional literacy performance. Taken together, the overall effect size for preschool writing instruction was $g=.44,95 \%$ CIs $[.27, .60]$, suggesting that preschool writing instruction enhanced children's early literacy outcomes (see Figure 2). ${ }^{3}$ Furthermore, these interventions can be integrated with many existing instructional strategies in early reading skills and embedded in the comprehensive curricula without assuming greater amount of class time. Several caveats need to be attached to this conclusion, which are discussed within the Limitations and Future Directions section below.

$<$ INSERT FIGURE 2>

Although only one maturationist study (Neuman \& Roskos, 1992) was found examining the effects of adding print materials to the literacy environment without added adult involvement, the large effect size $(g=.94)$ may imply that environments rich in print and language experiences hold promise as a means to promote lengthier and more complex literacy-related

\footnotetext{
${ }^{3}$ The overall effect size was calculated based on 19 intervention conditions by excluding the three outliers.
} 
play. Specifically, this study suggests the importance of providing literacy objects within play settings that can stimulate and encourage children to participate in meaningful literacy behaviors. In addition to highlighting the benefits of enhanced literacy environments, adult involvement was supported as a strong predictor of literacy gains across studies especially when constructivist/interactionist interventions were used. The majority of these intervention conditions produced medium-large effect sizes and the effect sizes of Morrow's studies (examining the effects of adult involvement versus no adult involvement) were extremely high. These studies suggest that teachers who provide guidance or scaffolding and embed explicit instruction within the context of authentic writing activities are likely to facilitate young children's early literacy development.

The majority of environmentalist/behaviorist interventions (i.e., teacher-directed instruction) showed a small to medium effect size and focused on increasing children's abilities related to specific early literacy skills (e.g., alphabet knowledge, print concepts, fine motor skills) rather than general literacy behaviors (e.g., book handling, scribbles, pretend reading) examined in many of the constructivist/interactionist studies. Although significant findings from this group of studies were limited, analyses indicate that environmentalist/behaviorist interventions are especially beneficial for young children experiencing difficulty in the attainment of early writing skills. One plausible explanation is that at-risk children may require explicit teaching that directs their attention to a range of emergent literacy skills through directive instructional opportunities (Justice \& Kaderavek, 2004).

\section{Limitations and Future Directions}

Clearly, from the small number of studies $(n=18)$ included in this systematic review of the literature, an extensive gap exists in the research on preschool writing. As way of 
comparison, in a meta-analysis conducted by Graham and colleagues (2012), the researchers found 115 experimental and quasi-experimental writing intervention studies in the elementary school setting (ranging from grades 1-6). The small number of experimental and quasiexperimental studies available on preschool writing limited the number of studies that we could consider for systematic review and meta-analysis inclusion. For example, only one maturationist study (Neuman \& Roskos, 1992) was found which investigated the effects of enhancing the physical environment with literacy materials. In addition, only one study was found that investigated an intervention solely focused on writing instruction (Hall et al., 2014). Other studies investigated multifaceted interventions (e.g., comprehensive literacy curriculums) making it hard to discern the effects of preschool writing exclusively. Half of the studies $(n=9)$ also defined writing narrowly as a set of explicit skills (e.g., name writing, handwriting), making it difficult to generalize results to classrooms engaging in more holistic forms of writing instruction. Within the different philosophical approaches, no more than four studies were found to support each type of writing intervention (e.g., handwriting, letter writing, name writing).

Several additional limitations must be acknowledged as part of this systematic review of the literature. One, we do not claim to have included every experimental and quasi-experimental research study on writing interventions conducted at the preschool level. The included studies were limited to research on writing interventions conducted from 1990-2013 and were published within one of the five search engines listed previously. Two, some of the studies included in this systematic review lacked details in their descriptions of the writing interventions, the fidelity of implementation, the specific writing materials and tools used, and the structure and length of professional development training. Three, the included empirical studies were limited by how researchers defined and interpreted writing for preschool children ages three to five (i.e., 
familiarity with writing implements, conventions, and emerging skills to communicate attitudes and ideas through written representations, symbols, and letters). Four, due to the lack of available studies, the difficulty in parsing out the writing component within the multifaceted interventions, and the variety of dependent variables, we found it problematic to issue any sound conclusions in regard to the impact of instructional strategies for teaching writing related to students' early literacy outcomes. Finally, we found considerable variability in control conditions, which may be related to variability of effects for preschool writing interventions. Thus, the findings obtained from this study need to be interpreted with caution.

We have presented the results of a systematic search and review of the research literature that we believe are characteristic of the kinds of preschool writing research being conducted. We encourage other researchers to continue examining the influence of preschool writing interventions in order to deepen our current understanding of effective practices and provide evidence-based research for teachers in the field. Specifically, future research is needed investigating instructional strategies in writing independent of other early literacy skills (e.g., phonemic awareness, alphabet knowledge). In addition, further research is needed on the enhancement of the physical literacy environment to determine what types of materials, their accessibility, and how teachers might rotate materials to lead to increases in children's literacy development. Also, this systematic review highlights the need to examine the effects of different types of adult involvement (e.g., scaffolding, guiding, direct instruction) during writing activities on children's early literacy outcomes (including children's motivation and engagement to read and write). Finally, most of the studies identified during this systematic review focused on typically developing preschool children. More research is needed for young children with disabilities and for children who are English Language Learners. 


\section{Conclusion}

Based on the results of this systematic review of literature on preschool writing, we conclude that an extensive gap in the experimental and quasi-experimental research on preschool writing exists. Current preschool studies have investigated various interventions and instructional strategies in preschool writing ranging along a continuum of adult involvement, yet represented by three distinct philosophical approaches (i.e., maturationist, constructivist/interactionist, and environmentalist/behaviorist). Within these three approaches, studies that incorporated interventions varied significantly in their levels of teacher direction, from no adult involvement to direct instruction. Although dependent variables differed greatly among the 18 studies included in this systematic review, the effectiveness of writing instruction on children's emergent literacy outcomes was found to be relatively large in 11 out of 22 intervention conditions regardless of the philosophical approach supporting writing instruction. This study represents a first step in examining preschool writing instruction, makes an important contribution to the literature, and suggests a strong need for future research in the area of preschool writing instruction. 


\section{References}

References marked with an asterisk indicate studies included in the meta-analysis.

* Aram, D. (2006). Early literacy interventions: The relative roles of storybook reading, alphabetic activities, and their combination. Reading and Writing, 19, 489-515. doi: $10.1007 / \mathrm{s} 11145-006-9005-2$

* Aram, D., \& Biron, S. (2004). Joint storybook reading and joint writing interventions among low SES preschoolers: differential contributions to early literacy. Early Childhood Research Quarterly, 19, 588-610. doi:10.1016/j.ecresq.2004.10.003

Atwell, N. (1987). In the middle: Writing, reading, and learning with adolescents. Portsmouth, NH: Heinemann.

*Bernhard, J. K., Winsler, A., Bleiker, C., Ginieniewicz, J., \& Madigan, A. L. (2008). "Ready my story!" Using the early authors program to promote early literacy among diverse, urban preschool children in poverty. Journal of Education for Students Placed at Risk, 13(1), 76-105. doi: 10.1080/10824660701860458

Borenstein, M., Hedges, L. V., Higgins, J. P., \& Rothstein, H. R. (2011). Introduction to metaanalysis. West Sussex, UK: Wiley.

Brotherton, S., \& Williams, C. (2002). Interactive writing instruction in a first grade Title I literacy program. Journal of Reading Education, 27(3), 8-19.

Calkins, L. M. (1983). Lessons from a child: On the teaching and learning of writing. Exeter, NH: Heinemann.

Calkins, L. M. (1986). The art of teaching writing. Portsmouth, NH: Heinemann.

*Christie, J. F., \& Enz, B. (1992). The effects of literacy play interventions on preschoolers' play patterns and literacy development. Early Education and Development, 3(3), 205-220. 
Cohen, J. (1988). Statistical power analysis for the behavioral sciences (2nd ed.). Hillsdale, NJ: Erlbaum.

Craig, S. A. (2006). The effects of an adapted interactive writing intervention on kindergarten children's phonological awareness, spelling, and early reading development: A contextualized approach to instruction. Journal of Educational Psychology, 98(4), 714731. doi:10.1037/0022-0663.98.4.714

*DeBaryshe, B. D., \& Gorecki, D. M. (2007). An experimental validation of a preschool emergent literacy curriculum. Early Education and Development, 18(1), 93-110.

Demarest, E. J., Reisner, E. R., Anderson, L. M., Humphrey, D. C., Farquhar, E., \& Stein, S. E. (1993). Review of research on achieving the nation's readiness goal. Washington, DC: U.S. Department of Education.

DeVries, R., Zan, B., Hildebrandt, C., Edmiaston, R., \& Sales, C. (2002). Developing Constructivist Early Childhood Curriculum: Practical Principles and Activities. New York, NY: Teachers College Press.

Dodge, D. T., Colker, L. J., \& Heroman, C. (2002). Connecting content, teaching, and learning: The Creative Curriculum for preschool. Washington, DC: Teaching Strategies, Inc.

* Donica, D. K., Goins, A., \& Wagner, L. (2013). Effectiveness of handwriting readiness programs on postural control, hand control, and letter and number formation in head start classrooms. Journal of Occupational Therapy, Schools, \& Early Intervention, 6(2), 8193. doi: 10.100/19411243.2013.810938

Epstein, A. S. (2007). Essentials of active learning in preschool: Getting to know the High/Scope curriculum. Ypsilanti, MI: High/Scope Press.

Gesell, A. (1940). The first five years of life. New York: Harper \& Brothers. 
Graham, S., McKeown, D., Kiuhara, S., \& Harris, K. R. (2012). A meta-analysis of writing instruction for students in the elementary grades. Journal of Educational Psychology, 104(4), 879-896. doi: 10.1037/a0029185

Graves, D. H. (1983). Writing: Teachers and children at work. London, UK: Heinemann Educational Books.

Hall, A. H., Toland, M. D., Grisham-Brown, J., \& Graham, S. (2014). Exploring interactive writing as an effective practice for increasing head start students' alphabet knowledge skills. Early Childhood Education Journal, 42(6), 423-430. doi:10.1007/s10643-013$0594-5$

Halle, T. G., Hair, E. C., Wandner, L. D., \& Chien, N. C. (2012). Profiles of school readiness among four-year-old Head Start children. Early Childhood Research Quarterly, 27, 613626.

Hand, A., \& Nourot, P. (1999). First class, a guide for early primary education, preschoolkindergarten-first grade. Sacramento, CA: California Department of Education.

Justice, L. M., \& Kaderavek, J. N. (2004). Embedded-explicit emergent literacy intervention background and description of approach. Language, Speech, and Hearing Services in Schools, 35(3), 201-211.

* Justice, L. M., Chow, S. M., Capellini, C., Flanigan, K., \& Colton, S. (2003). Emergent literacy intervention for vulnerable preschoolers: Relative effects of two approaches. American Journal of Speech-Language Pathology, 12, 320-332.

Kissel, B., Hansen, J., Tower, H., \& Lawrence, J. (2011). The influential interactions of prekindergarten writers. Journal of Early Childhood Literacy, 11(4), 425-452. 
* Longcamp, M., Zerbato-Poudou, M. T., \& Velay, J. L. (2005). The influence of writing practice on letter recognition in preschool children: A comparison between handwriting and typing. Acta psychologica, 119(1), 67-79. doi: 10.1016/j.actpsy.2004.10.019

Lonigan, C. J., \& Shanahan, T. (2009). Executive summary: Developing early literacy: Report of the National Early Literacy Panel. Retrieved from http://lincs.ed.gov/publications/pdf/NELPSummary.pdf

* Lonigan, C. J., Farver, J. M., Phillips, B. M., \& Clancy-Menchetti, J. (2011). Promoting the development of preschool children's emergent literacy skills: A randomized evaluation of a literacy-focused curriculum and two professional development models." Reading and Writing, 24(3), 305-337. doi: 10.1007/s11145-009-9214-6

* Lust, C. A., \& Donica, D. K. (2011). Effectiveness of a handwriting readiness program in Head Start: A two-group controlled trial. The American Journal of Occupational Therapy, 65(5), 560-568.

Mariage, T. V. (2001). Features of an interactive writing discourse; Conversational involvement, conventional knowledge, and internalization in the "morning message". Journal of Learning Disabilities, 34(2), 172. doi:10.1177/002221940103400206

Marulis, L. M., \& Neuman, S. B. (2010). The effects of vocabulary intervention on young children's word learning: a meta-analysis. Review of Educational Research, 80(3), 300335.

*Morrow, L. M. (1990). Preparing the classroom environment to promote literacy during play. Early Childhood Research Quarterly, 5(4), 537-554.

National Early Literacy Panel. (2008). Developing early literacy: A scientific synthesis of 
early literacy development and implications for intervention. Jessup, MD: National Institute for Literacy.

National Governors Association Center for Best Practices \& Council of Chief State School Officers. (2010). Common Core State Standards for English Language Arts and Literacy in History/Social Studies, Science, and Technical Subjects: About the standards.

Washington, DC: Authors. Retrieved from www.corestandards.org/about-the-standards

Neuendorf, K. (2002). The content analysis guidebook. Thousand Oaks, CA: Sage.

*Neuman, S. B., \& Roskos, K. (1992). Literacy objects as cultural tools: Effects on children's literacy behaviors in play. Reading Researching Quarterly, 27(3), 202-225.

*Neuman, S. B., \& Roskos, K. (1993). Access to print for children of poverty: Differential effects of adult mediation and literacy-enriched play settings on environmental and functional print tasks. American Education Research Journal, 30(1), 95-122.

* Neumann, M. M., Hood, M., \& Ford, R. M. (2013). Using environmental print to enhance emergent literacy and print motivation. Reading and Writing, 26(5), 771-793. doi: $10.1007 / \mathrm{s} 11145-012-9390-7$

Olsen, J.Z., \& Knapton, E. F. (2008). Handwriting Without Tears Pre-K teacher's guide. Cabin John: MD: Handwriting Without Tears.

Petticrew, M., \& Roberts, H. (2008). Systematic reviews in the social sciences: A practical guide. Hoboken, NJ: John Wiley \& Sons.

Puranik, C., Al Otaiba, S., Sidler, J., \& Greulich, L. (2014). Exploring the amount and type of writing instruction during language arts instruction in kindergarten classrooms. Reading and Writing, 27(2), 213-236. doi: 10.1007/s11145-013-9441-8 
Puranik, C., S., \& Lonigan, C. J. (2011). From scribbles to scrabble: Preschool children's developing knowledge of written language. Reading and Writing, 24, 567-589. doi: $10.1007 / \mathrm{s} 11145-009-9220-8$

Puranik, C., S., Lonigan, C., J., \& Kim, Y.-S. (2011). Contributions of emergent literacy skills to name writing, letter writing, and spelling in preschool children. Early Childhood Research Quarterly, 26(4), 465-474. doi: http://dx.doi.org/10.1016/j.ecresq.2011.03.002

* Register, D. (2001). The effects of an early intervention music curriculum on prereading/writing. Journal of Music Therapy, 3, 239-248.

Roth, K. (2009). Interactive Writing: Investigating the effectiveness of a dynamic approach to writing instruction for first graders. (Doctoral dissertation). Retrieved from Proquest database. (Accession Number 304894167)

Schwarzer, G. (2013). meta: Meta-Analysis with R. R package version 3.1-2. Retrieved from http://cran.r-project.org/web/packages/meta/index.html.

Shore, L. (2003). Shore handwriting screening for early handwriting development: Examiner's manual. Chaska, MN. Harcourt Assessment, Inc.

Snow, C. E., Burns, M. S., \& Griffin, P. (Eds.). (1998). Preventing reading difficulties in young children. Washington, DC: National Research Council.

* Standley, J. M., \& Hughes, J. E. (1997). Evaluation of an early intervention music curriculum for enhancing prereading/writing skills. Music Therapy Perspectives, 15, 79-86.

Sulzby, E. (1985). Children's emergent reading of favorite storybooks: A developmental study. Reading Research Quarterly, 20, 458-481. 
Tolchinsky, L. (2014). From text to language and back: The emergence of written language. In C. MacArthur, S. Graham, \& J. Fitgerald (Eds.), Handbook of writing research (2nd Ed.). NY: Guilford.

U.S. Department of Health and Human Services. (2010). The Head Start child development and early learning framework. Retrieved from http://eclkc.ohs.acf.hhs.gov/hslc/ttasystem/teaching/eecd/Assessment/Child\%20Outcomes/HS_Revised_Child_Outcomes_Fr amework(rev-Sept2011).pdf

* Vera, D. (2011). Using popular culture print to increase emergent literacy skills in one highpoverty urban school district. Journal of Early Childhood Literacy, 11(3), 307-330. doi: $10.1177 / 1468798411409297$

Vygotsky, L. S. (1978). Mind in society: The development of higher psychological processes. Cambridge, MA: Harvard University Press.

Whitehurst, G. J., \& Lonigan, C. J. (1998). Child development and emergent literacy. Childhood Development, 69, 848-872. doi:10.2307/1132208

Zigler, E. F. (2000). Foreword. In J. P. Shonkoff \& S. J. Meisels (Eds.), Handbook of early childhood intervention (pp. XI-XV). Cambridge, NY: Cambridge University Press. 